Bull. Chem. Soc. Ethiop. 2019, 33(2), 349-358.

ISSN 1011-3924

(c) 2019 Chemical Society of Ethiopia and The Authors

Printed in Ethiopia

DOI: https://dx.doi.org/10.4314/bcse.v33i2.15

\title{
MICROWAVE DIELECTRIC RELAXATION \& POLARIZATION STUDY OF BINARY MIXTURE OF METHYLETHYLKETONE WITH NITROBENZENE
}

\author{
Aruna P. Maharolkar ${ }^{1 *}$, A.G. Murugkar ${ }^{2}$, P.W. Khirade ${ }^{2}$ and S.C. Mehrotra ${ }^{3}$ \\ ${ }^{1}$ G. S. Mandal's Marathwada Institute of Technology, Aurangabad (M.S.)-431004, India \\ ${ }^{2}$ Department of Physics, Dr. B. A. M. University, Aurangabad, (M.S.)-431004, India \\ ${ }^{3}$ Department of Electronics and Computer Science, Dr. B. A. M. University, Aurangabad \\ 431004, Maharashtra, India
}

(Received April 22, 2018; Revised April 5, 2019; Accepted April 19, 2019)

\begin{abstract}
Present paper reveals detailed study of dielectric relaxation and dielectric polarization and physicochemical study of binary polar-polar liquid mixture i.e. dielectric constant, relaxation time, viscosity, density of methylethylketone (MEK) with nitrobenzene (NB) at $303 \mathrm{~K}$. The measured dielectric and physicochemical parameters employed to acquire additional derived properties like Bruggeman factor, molar refraction and excess properties like static dielectric constant, excess inverse relaxation time, excess molar volume, excess viscosity, excess molar refraction, Gibbs free energy, and enthalpy of activation. The variation of this parameters with composition of these quantities has been used to explain the type, strength and nature of intermolecular interactions between MEK $+\mathrm{NB}$ binary mixture. Attained results authenticate that there are strong hydrogen-bond interactions between unlike molecules of different groups of MEK+NB mixtures and that 1:1 complexes are produced and strength of intermolecular interaction rises with rise in concentration of MEK.
\end{abstract}

KEY WORDS: Bruggeman factor, Excess inverse relaxation time, Dielectric polarization

\section{INTRODUCTION}

Dielectric relaxation study furnishes detail insights of intermolecular interactions of binary liquid mixture [1-3]. It also provides valuable information regarding presence of bonding, strength of bonding between homogenous or heterogenous binary liquid mixtures [1-2]. This study is very important because it also gives insights about how a functional group of a molecule reacts with functional group of another molecule [1].

Preference of ideal solvent for given solute is versatile problem in front of various types of industries like ceramics, pharmaceuticals and research and development [4-8]. Benzene group acts as good solvent for ketone group. Nitrobenzene is good solvent as majority of ketones are soluble in it. Presence of nitro group to benzene which is present in nitrobenzene taken as solvent, renders a considerable effect on the dielectric properties that shapes enhanced solubility properties [9-11]. Such phenomenon is more prominent in the solutions of nitrobenzene with ketone group. Polar molecules like nitrobenzene constitute a part of industrial reagents [11] and distinct figure of merits/demerits of a binary or higher complex mixtures are required for designing of efficient chemical process. This necessity warrants an in depth look into the physical properties of binary mixture of nitrobenzene + ketone system. This communication reports static dielectric constant $(\varepsilon)$, relaxation time $(\tau)$, viscosity $(\eta)$ and density $(\rho)$ and derived parameters like molar volume, molar refraction, Bruggeman factor, polarization and excess parameters like excess static dielectric constant, excess inverse relaxation time, excess molar volume, excess viscosity, excess molar refraction, and excess molar polarization. Excess properties plays key role in gaining insight and type of interactions between molecular structures. Solubility of the liquid is directly associated with the dielectric constant of the liquid

*Corresponding author. aruna_physics@rediffmail.com

This work is licensed under the Creative Commons Attribution 4.0 International License 
[3, 10-12]. Literature survey reveals that dielectric study of alcohols, ionic liquids, glycols, sulfates, diallyl sulphoxide, benzyl alcohol as a solvent has been carried out but dielectric study of MEK and NB has been rarely carried out [12-26]. So the study of MEK with NB is essential and hence carried out in this study.

\section{EXPERIMENTAL}

\section{Materials}

Both MEK and NB were acquired from analytical reagent grade and are obtained from Merck (99.99). These chemical was applied without further purification as purities were greater than $99 \%$. The solutions were prepared at various comparable volume percentages of MEK in NB in steps of $10 \%$ at room temperature. These concentrations were prepared for $5 \mathrm{~mL}$ solution samples at room temperature, assuming ideal mixing nature, with an accuracy $\pm 0.0006 \mathrm{~mL}$.

\section{Measurements}

TDR setup and data acquisition. The complex permittivity spectra were studied with the time domain reflectometry (TDR) technique as explained in [10-15]. The Hewlett Packard HP 54750 sampling oscilloscope with HP54754A TDR plug in module has been used.

Density measurement. The density was measured using portable digital density meter (MEK-35, Anton Paar) with accuracy $0.0001 \mathrm{~g} / \mathrm{cm}^{3}$.

Viscosity measurements. Viscosity was measured using Brookfield Viscometer (Brookfield Viscometer, Model: LV DV-II+ Pro, Cone-plate Model with CPE-40 spindle) with accuracy $0.01 \mathrm{cP}$.

Refractive indices. Refractive indices were measured using a thermostatically controlled Abbe's refractometer with an accuracy of \pm 0.001 .

\section{Data analysis}

Excess parameters. The general formula for calculating the excess parameters [15-32] is given below

$$
A^{E}=A_{m}-\left(x_{A} M_{1}+x_{B} M_{2}\right)
$$

where, $A^{E}$ is the excess parameter such as excess density $x_{A}$ mole fraction of solute and $x_{B}$ is mole fraction of solvent.

Bruggeman factor. Bruggeman's formula [4] can be employed as the important proof of presence intermolecular interactions in binary mixtures. The total volume of the solute-solvent interactions and is important shown by the deviation in linearity of the Bruggeman factor.

Equation 2 gives that static permittivity of the binary mixtures $\left(\varepsilon_{\mathrm{sm}}\right)$, solute $\left(\varepsilon_{\mathrm{sA}}\right)$ and solvent $\left(\varepsilon_{\mathrm{sB}}\right)$ are associated to the volume fraction of solvent $(\mathrm{V})$, which specified the interaction among solvent and solute in the mixture is shown as:

$$
f_{\mathrm{B}}=\left(\frac{\varepsilon_{\mathrm{sm}}-\varepsilon_{\mathrm{sB}}}{\varepsilon_{\mathrm{SA}}-\varepsilon_{\mathrm{sB}}}\right)\left(\frac{\varepsilon_{\mathrm{sA}}}{\varepsilon_{\mathrm{sm}}}\right)^{1 / 3}=1-V
$$


As per this equation, a linear relationship is expected between the Bruggeman factor $f_{B}$ and the volume (V). Any deviation from this linear relation indicates molecular interactions. The excess parameters were fitted to the Redlich-Kister equation [13-16]. The quantitative picture can be visualized by fitting excess properties.

\section{RESULTS AND DISCUSSION}

Table 1 depicts variation of measured parameters like dielectric constant, relaxation time, density, and viscosity with concentration of MEK. Nonlinear variation of measured parameters with concentration indicates presence of intermolecular interactions between MEK in NB. Table 2 shows very less value of standard deviation (error) indicate authenticity of data. Table 3 proves that experimental values in this paper are in good agreement with literature values.

Table 1. Density, viscosity, static dielectric constant, and relaxation time of MEK+NB.

\begin{tabular}{|c|c|c|c|c|c|}
\hline $\begin{array}{c}\text { Volume fraction of } \\
\text { MEK }\end{array}$ & $\begin{array}{c}\text { Density } \\
\left(\mathrm{g} / \mathrm{cm}^{3}\right)\end{array}$ & $\begin{array}{c}\text { Viscosity } \\
(\mathrm{cP})\end{array}$ & RI & $\begin{array}{c}\text { Dielectric } \\
\text { constant }\end{array}$ & $\begin{array}{c}\text { Relaxation } \\
\text { time }(\mathrm{ps})\end{array}$ \\
\hline 0 & 0.936 & 1.63 & 1.411 & 34.82 & 32.43 \\
\hline 0.1 & 0.927 & 1.48 & 1.407 & 33.29 & 32.48 \\
\hline 0.2 & 0.915 & 1.26 & 1.403 & 31.90 & 32.87 \\
\hline 0.3 & 0.904 & 1.04 & 1.399 & 30.71 & 32.99 \\
\hline 0.4 & 0.900 & 0.86 & 1.395 & 29.51 & 33.03 \\
\hline 0.5 & 0.888 & 0.71 & 1.391 & 28.74 & 33.15 \\
\hline 0.6 & 0.865 & 0.67 & 1.386 & 26.35 & 33.99 \\
\hline 0.7 & 0.846 & 0.58 & 1.382 & 24.41 & 35.12 \\
\hline 0.8 & 0.817 & 0.50 & 1.378 & 22.17 & 36.27 \\
\hline 0.9 & 0.797 & 0.40 & 1.374 & 20.18 & 37.04 \\
\hline 1 & 0.769 & 0.35 & 1.370 & 18.28 & 38.12 \\
\hline
\end{tabular}

Table 2. R K coefficients (aj coefficients) and standard error $(\sigma)$ foe excess parameters.

\begin{tabular}{|l|l|l|l|l|l|}
\hline Parameter & $\mathrm{a} 0$ & $\mathrm{a} 1$ & $\mathrm{a} 2$ & $\mathrm{a} 3$ & $\mathrm{a} 4$ \\
\hline Excess molar volume & -9.259 & -1.59 & $1.13 \times 10^{1}$ & $6.85 \times 10^{-1}$ & $3.80 \times 10^{-1}$ \\
\hline $\begin{array}{l}\text { Excess static dielectric } \\
\text { constant }\end{array}$ & 6.8675 & 1.865 & -9.847 & -1.818 & 0.21 \\
\hline Excess relaxation time & $5.67 \times 10^{3}$ & $3.86 \times 10^{-4}$ & $-5.85 \times 10^{-3}$ & $-2.00 \times 10^{-3}$ & $1.58 \times 10^{-4}$ \\
\hline Excess viscosity & -1.0148 & 0.6185 & 0.8514 & -1.598 & $1.32 \times 10^{-2}$ \\
\hline Excess molar refraction & -3.00 & -0.312 & 2.702 & 0.131 & $9.01 \times 10^{-2}$ \\
\hline Excess molar polarization & $-7.78 \times 10^{-1}$ & $-3.74 \times 10^{-1}$ & $9.42 \times 10^{-1}$ & $3.39 \times 10^{-1}$ & $2.13 \times 10^{-2}$ \\
\hline
\end{tabular}

Table 3. Comparison of measured parameters with literature values of density, viscosity, static dielectric constant, and relaxation time.

\begin{tabular}{|l|c|c|c|c|}
\hline & \multicolumn{2}{|c|}{ NB } & \multicolumn{2}{c|}{ MEK } \\
\hline Parameter & $\begin{array}{c}\text { Experimental } \\
\text { study }\end{array}$ & Literature & $\begin{array}{c}\text { Experimental } \\
\text { study }\end{array}$ & Literature \\
\hline Density (g/cm3) & 0.936 & 0.852 at 313 K [29] & 0.769 & $0.7956[27]$ \\
\hline Viscosity (cP) & 1.630 & $1.683[30]$ & 0.350 & 0.43 at 20 ${ }^{\circ} \mathrm{C}[28]$ \\
\hline RI & 1.411 & $1.479[31]$ & 1.370 & $1.373[27]$ \\
\hline Dielectric constant & 34.82 & $34.89[32]$ & 18.28 & $18.27[27]$ \\
\hline Relaxation time (ps) & 32.43 & -- & 38.12 & $38.1[27]$ \\
\hline
\end{tabular}


Figure 1 shows negative deviation of excess molar volume in MEK $+\mathrm{NB}$ mixtures illustrates the structural contribution, of constituents occurring by appropriate geometrical fitting in this case, i.e. better interstitial spacing of solute and solvent in the system [4-7]. The molecules of MEK assist with nitrobenzene are confirmed from our study. This cooperation gives the decrease in molar volume of the mixture. Leading to the formation of tightly packed hydrogenbonded aggregates (between unlike molecules) [5-7]. Negative value also indicates that the solute acts as a structure maker. The maximum deviation of excess molar volume shows the strength of hydrogen bonded interaction [6-7]. The negative $V^{\mathrm{E}}$ values of the system are attributed to interstitial accommodation of MEK molecules in the H-bonded network of nitrobenzene [6-7].

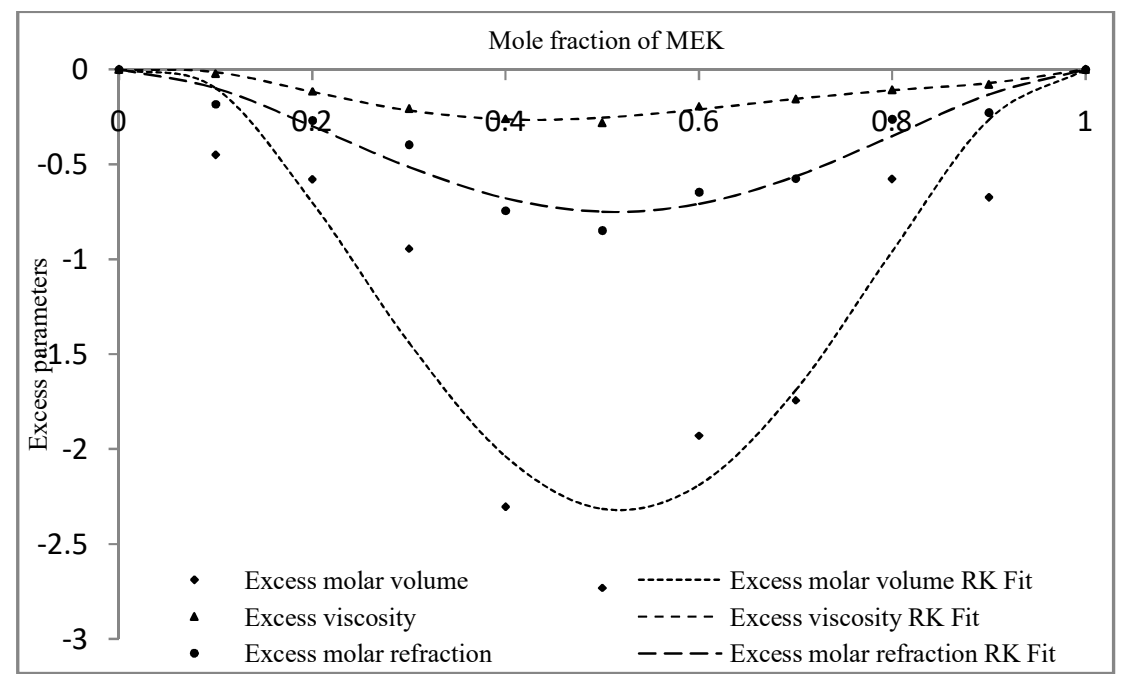

Figure 1. Excess molar volume, viscosity and molar refraction of MEK+nitrobenzene.

Figure 1 gives excess viscosity of MEK+NB. Negative values of $\eta^{\mathrm{E}}$ for the mixture can be explained on the basis of complex formation between different molecules through hydrogen bonding [6-7]. Charge transfer, hydrogen bonding forces leading to the formation of complex species between unlike molecules results in negative deviation. Negative deviation of $\eta^{\mathrm{E}}$ also indicates that the interaction between binary mixtures is strong[6-7].

The concentration $X_{\mathrm{MEK}}=0.5$ corresponding to the maximum of the excess viscosity for MEK-NB mixtures (Figure 1) suggests that complexes of MEK:NB (1:1) are implicated in a cooperative hetero-molecular viscous flow process [6-7]. The negative $\eta^{\mathrm{E}}$ values suggest that the flow process is facilitated by the hetero-molecular interactions in these systems [6-7]. A large change in the magnitude of $\eta^{\mathrm{E}}$ values with concentration indicates that the number of complex species contributing to the viscous flow is strongly governed by the molecular forces [6-7]. This may be due to intermolecular vibrations and compactness that may increase strength of the hydrogen bond connectivity of the MEK:NB (1:1) complex species, which facilitates their translational and rotational motion. The asymmetrical shape of the concentration dependent $\eta^{\mathrm{E}}$ plots. (Figure 1) indicates that the addition of a small amount of MEK to NB involves a more important effect on the breaking of their self-associated structures and simultaneously formation of a large number of MEK:NB (1:1) complex species, which contribute to the viscous flow process. 
The variation of excess molar refraction with mole fraction of MEK is shown in Figure 1. The values of excess molar refraction were negative over the entire range of concentration of MEK. It is a well known fact that the molar refraction is primarily dependent on composition and is little affected by temperature or pressure. At the same time excess molar refraction is almost independent of the physical state of the substance. Figure 1 shows that excess molar refraction $\left(R_{m}^{E}\right)$ is negative. The negative deviation of excess refractive index is a strong indication of interaction involving hydrogen bonding.

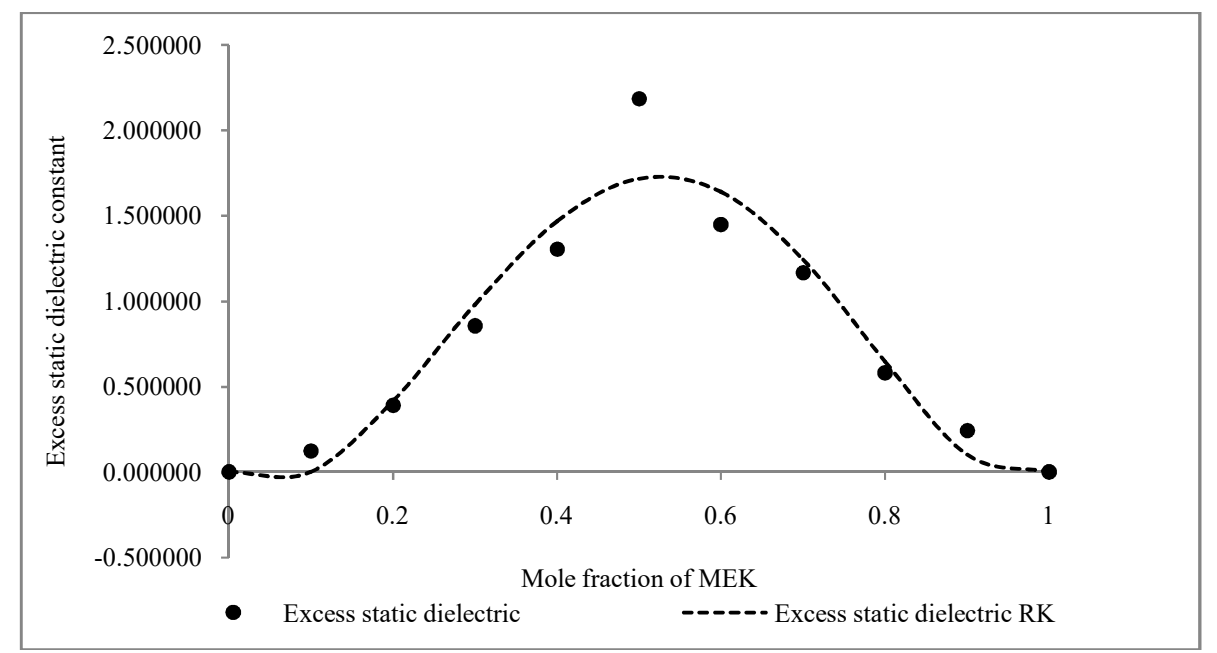

Figure 2. Excess static dielectric constant of MEK $+\mathrm{NB}$.

The positive value of excess static dielectric constant indicates as depited in Figure 2 that the solute and solvent interact in such a style so as to raise the effective dipole moment and leads to the creation of dimers. The excess static dielectric constant values of the binary mixtures of polar solvent is generally applied to obtain insight into the strength of hetero-molecular Hbonded structures and dipolar ordering and also the stoichiometric composition corresponding to the formation of a stable complex product [12]. The concentration, $X_{\text {MEK }}$ equivalent to the maximum magnitude of excess static dielectric constant, is (at) 0.50 (Figure 2) signifying the creation of a stable complex with 1:1 mole ratio, which controls their molecular dielectric polarization [11]. MEK molecule, when mixed with NB, cooperates with nitrobenzene molecule and thus there is possibility to creation of hydrogen bonding with each other. The positive excess static dielectric constant also indicates that MEK acts as a structure maker for another molecule during the cooperation with dipoles of similar orientation. Hence there is increase in the total number of parallel aligned effective dipoles that contribute to the mixture dielectric polarization.

Figure 3 depicts excess inverse relaxation time. The excess inverse relaxation time represents average broadening of dielectric spectra [16]. The inverse relaxation time correlation is applied from spectral line expansion (which is inverse of relaxation time) from the reverberating spectroscopy [16]. The excess inverse relaxation time provides details about the dynamics of solute-solvent interaction. Positive excess inverse relaxation time designates that the solute-solvent interaction has produced such a field that the effective dipoles rotate rapidly [15]. This rapid rotation of dipoles is due to specific interaction between MEK and NB. Thus, specific interaction produces field effect in such a way that obstructs dipole rotation.

Bull. Chem. Soc. Ethiop. 2019, 33(2) 


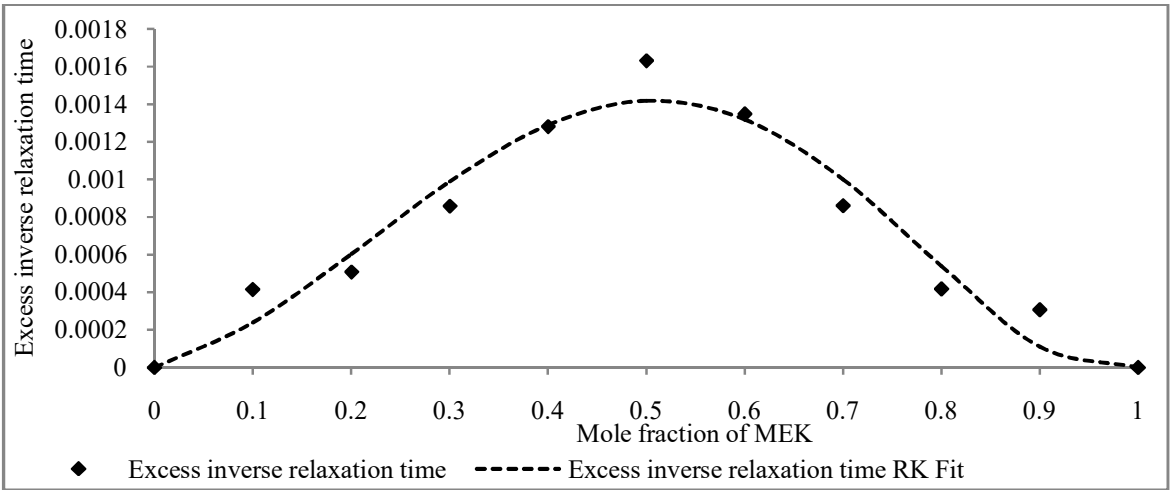

Figure 3. Excess inverse relaxation time of $\mathrm{MEK}+\mathrm{NB}$.

From Figure 4 it is observed that the value of Bruggeman factor $\left(f_{B}\right)$ departs from ideal line. The nonlinearity of the graph specifies existence of intermolecular interactions in the system. Ideally Bruggeman factor is 0.8 at that point value of volume fraction [volume fraction = $\left.\frac{V 1}{V 1+V 2}\right]$ should be 0.2 . but it is practically it is found that when Bruggeman factor is 0.8 he value of volume fraction is 0.4 here volume fraction $\frac{V 1}{V 1+V 2}$ is increased it means that total volume of mixture $\left(v_{1}+v_{2}\right)$ is decreased or reduced. Hence contraction of volume takes place due to hydrogen bonding. This is supported by figure 1 negative excess molar volume.

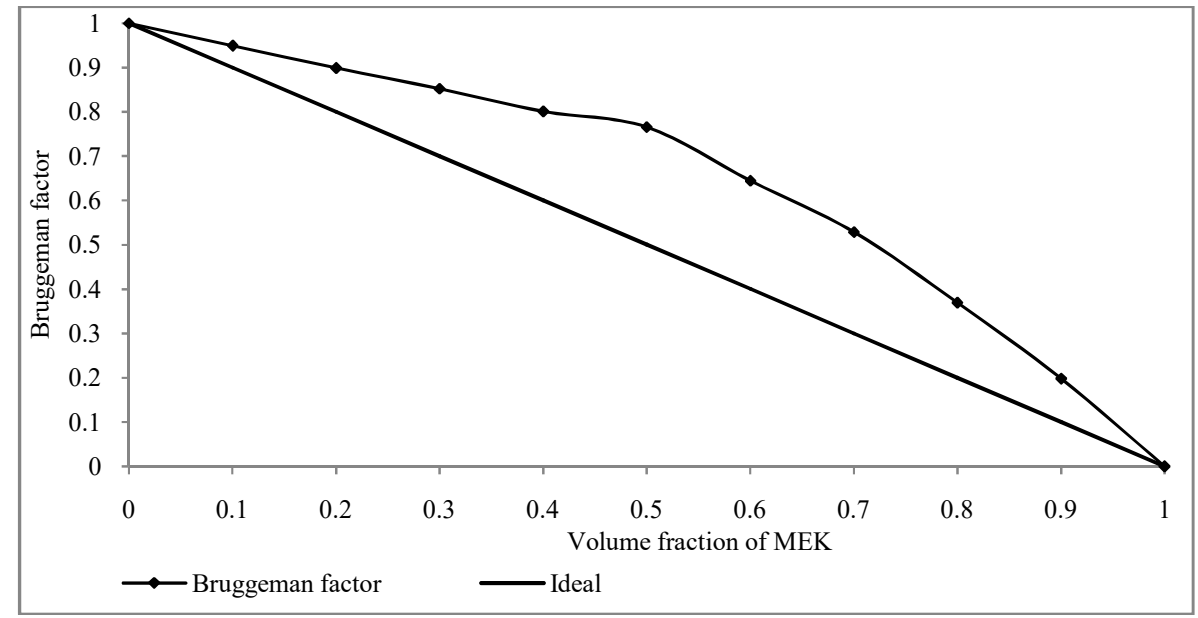

Figure 4. Bruggeman factor of MEK+NB.

Excess molar polarization (Figure 5) confers negative deviation which illustrates that MEK cooperates with NB and forms strong hydrogen bonded structures. 


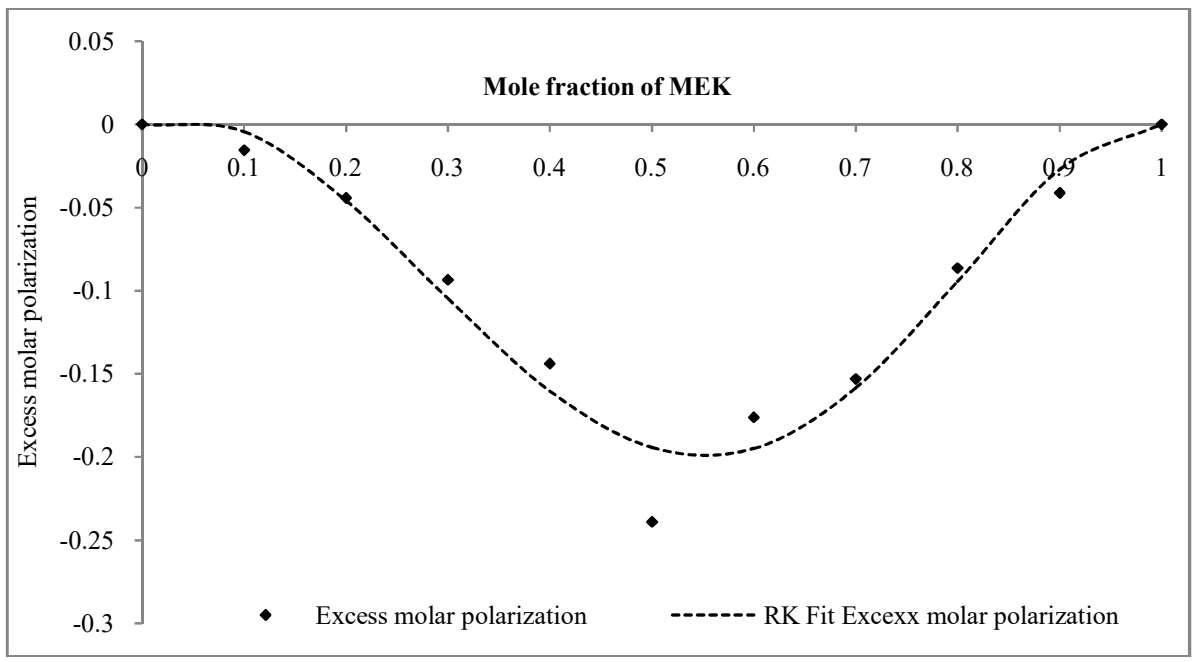

Figure 5. Excess molar polarization of $\mathrm{MEK}+\mathrm{NB}$.

Figure 6 depicts non leaner deviation of Gibbs free energy of MEK in NB it clearly indicates presence of strong intermolecular interactions between solute and solvent.

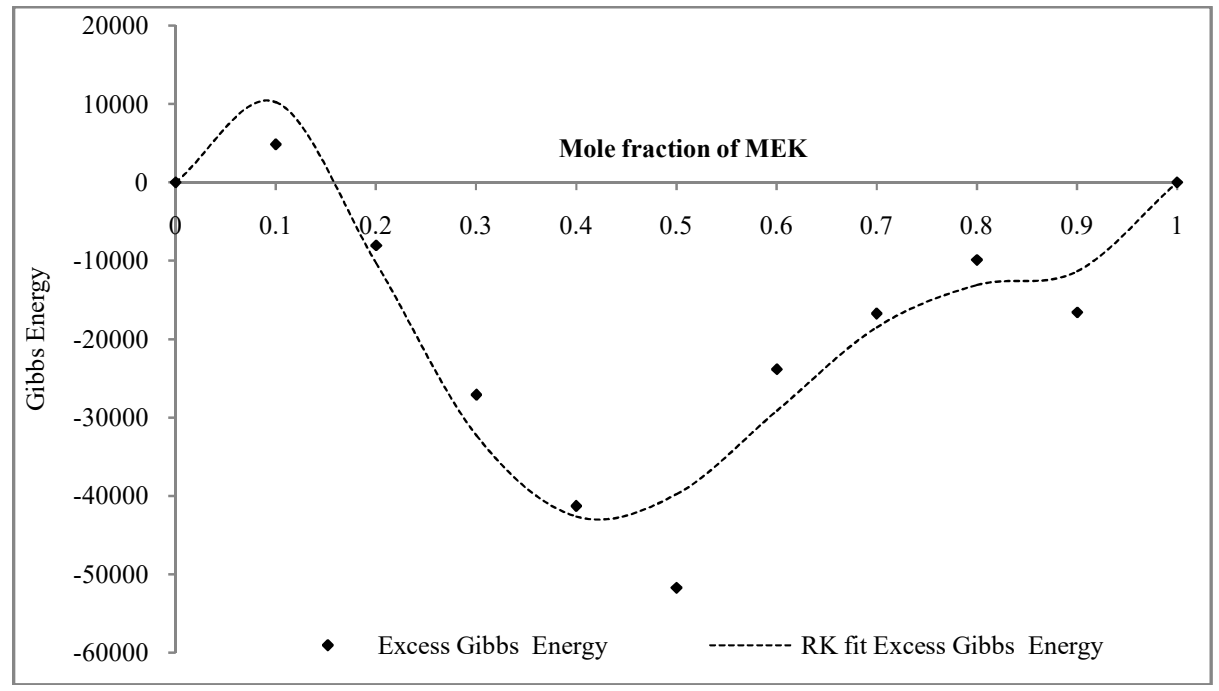

Figure 6. Excess Gibbs Energy for MEK+NB.

Figure 7 depicts variation of enthalpy of activation. Enthalpy of activation is obtained from Eyring's rate equation. The value of Enthalpy of activation gradually decreases with increase in volume fraction of MEK. This indicates that less energy is needed for dipole reorientation. Figure 8 gives structure of hydrogen bonding formation between MEK and NB. 


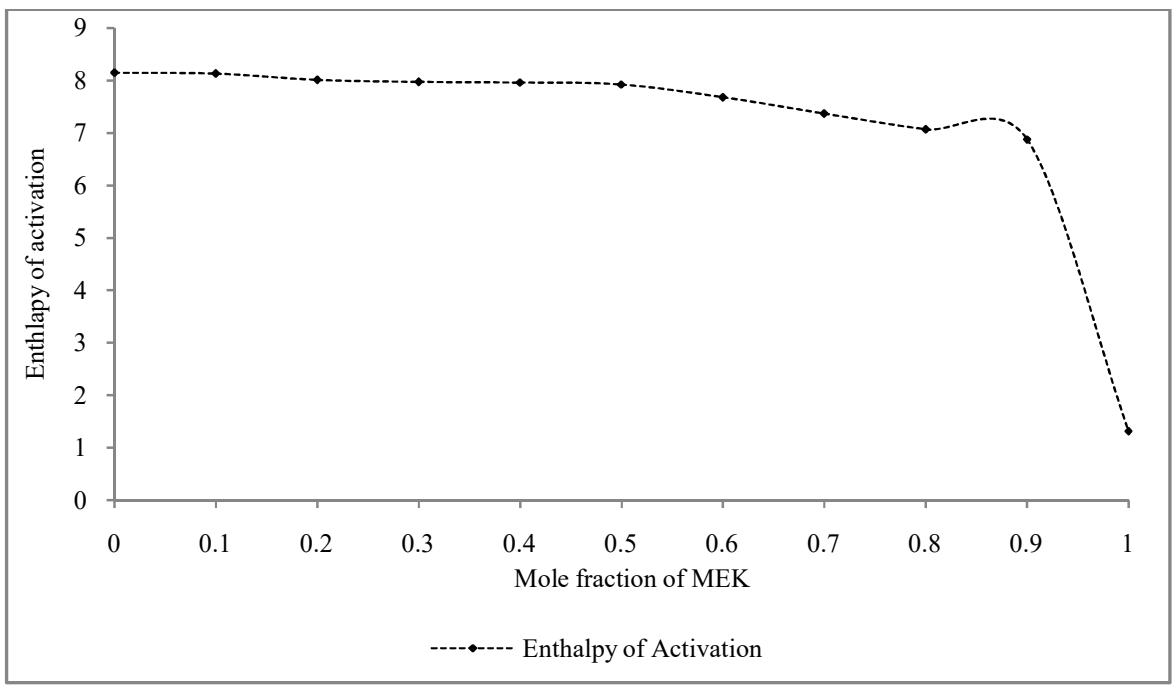

Figure 7. Enthalpy of Activation of MEK $+\mathrm{NB}$.

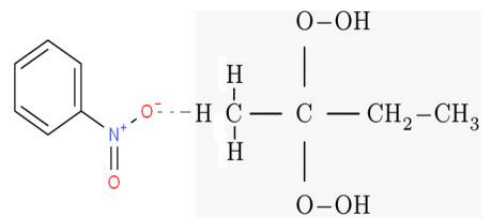

Figure 8. Hydrogen bonding interaction structure of MEK with NB.

\section{CONCLUSION}

Precise values of the static dielectric constant, relaxation time, viscosity, density, and refractive index of the MEK $+\mathrm{NB}$ binary mixtures were experimentally measured over the complete volume composition range at $\mathrm{T}=303 \mathrm{~K}$. The non-linear behavior of measured parameters against $\mathrm{X}_{\mathrm{MEK}}$ authenticates the production of heteromolecular $\mathrm{H}$-bonded complexes with a reduction in the effective number of parallel aligned dipoles in these binary mixtures. The 1:1 complexes of MEK and NB control the molecular dielectric polarization process, whereas MEK:NB (1:1) complexes controls the viscous flow process and their number per unit volume are strong MEK prejudiced by the temperature and concentration. Excess values of static dielectric constant and the deviation in the excess viscosity, excess inverse relaxation time, and excess molar volume from the mole-fraction mixture law were calculated for mixed solvents and these values were interpreted in relation to the $\mathrm{H}$-bond molecular interactions between unlike MEK $+\mathrm{NB}$ molecules. The measured and estimated values of the dielectric parameters confirm the H-bond molecular interactions decrease the number of effective parallel aligned dipoles with the formation of 1:1 complexes in MEK+NB mixed solvents. It has been noticed that excess molar volume is becoming more and more negative with corresponding increase in composition, such observation definitely leads to the conclusion that the strength of intermolecular interaction increases with composition. 


\section{REFERENCES}

1. Maharolkar, A.P.; Murugkar, A.G.; Khirade, P.W.; Mehrotra, S.C. Study of thermophysical properties of associated liquids at $308.15 \mathrm{~K}$ and 313.15 K. Russian J. Phys. Chem. A 2017, 91, 1710-1716.

2. Maharolkar, A.P.; Sudake, Y.S.; Kamble, S.P.; Murugkar, A.G.; Patil, S.S.; Khirade, P.W. Dielectric relaxation study of polar protic and aprotic solvent. Asian J. Chem. 2012, 12 , 5680-5682.

3. Murugkar, A.G.; Maharolkar, A.P. Investigation on some thermo physical properties of methanol and nitrobenzene binary mixtures. Rasayan J. Chem. 2014, 7, 39-43.

4. Maharolkar, A.P.; Sudake, Y.S.; Kamble, S.P.; Murugkar, A.G.; Patil, S.S.; Khirade, P.W. Dielectric study of allyl chloride with 2-butanol in microwave frequency range. American Institute of Physics Conference Proceeding 2013, 1536, 1129-1130.

5. Maharolkar, A.P.; Sudake, Y.S.; Kamble, S.P.; Tidar, A.L.; Murugkar, A.G.; Patil, S.S.; Khirade, P.W.; Mehrotra, S.C. Densities, viscosities and refractive indices of n-butanol + allyl chloride mixture at $298 \mathrm{~K}$. Int. J. Chem. 2010, 2, 250-260.

6. Maharolkar, A.P.; Khirade, P.W.; Murugkar, A.G. Physicochemical study of complex systems international journal of advanced engineering research and applications. $J . A d v$. Eng. Res. Applicat. 2016, 2, 390-396.

7. Maharolkar, A.P.; Murugkar, A.G.; Patil, S.S.; Khirade, P.W. Characterization of interaction in binary mixtures by dielectric analysis. Int. J. Pharm. Biosci. 2012, 3, 484444.

8. Maharolkar, A.P.; Murugkar, A.G.; Patil, S.S.; Khirade, P.W. Characterization of dominant hydrogen bonded complex structures. Asian J. Chem. 2013, 25, 937-940.

9. Patankar, S.L.; Maharolkar, A.P.; Patil, A.G.; Murugkar, A.G. Study of ultrasonic properties of nitromethane + DMSO at 313 K. Asian J. Res. Chem. 2017, 10, 523-525.

10. Redlich, O.; Kister, A.T. Algebraic representation of thermodynamic properties and the classification of solutions. Ind. Eng. Chem. 1948, 40, 345-348.

11. Krishnamurthi, P.; Thenmozhi, P.A. Ultrasonic studies of molecular interaction of alcohols with nonpolar solvents. J. Chem. Pharm. Res. 2012, 4, 4671-4676.

12. Maharolkar, A.P.; Murugkar, A.G.; Khirade, P.W. Study of intermolecular interactions in binary mixtures of ethanol in methanol. AIP Conference Proceedings, 2016, 1728, 0200381-0200384.

13. Maharolkar, A.P.; Murugkar, A.G.; Khirade, P.W. temperature dependent microwave dielectric characterization of associated liquids. J. Struct. Chem. 2018, 59, 1141-1147.

14. Maharolkar, A.P.; Murugkar, A.G.; Khirade, P.W. Microwave dielectric study of polar liquids at 298 K. AIP Conference Proceedings 2018, 1953, 020003-020006.

15. Maharolkar, A.P.; Khirade, P.W.; Murugkar, A.G.; Mehrotra, S.C. Physiochemical characterization of nitromethane with DMSO at $303.15,308.15,318.15,323.15 \mathrm{~K}$. Technol. Lett. 2016, 3, 5-8.

16. Mehrotra, S.C.; Boggs, J.E. Effect of collision induced phase shifts on the linewidth and line shift of rotational spectral lines. J. Chem. Phys. 1977, 66, 5306-5312.

17. Yang, M.; Liyan M.; Zhao, K.. Tmperature dependent dielectric relaxation of ionic liquid $\left([\mathrm{bmim}]\left[\mathrm{BF}_{4}\right]\right) /$ alcohol binary mixtures. New J. Chem. 2017, 41, 9330-9337.

18. Vishwam, T.; Shihab, S.; Murthy, V.K.; SieTiong, H.; Sastry, S.S. Microwave dielectric relaxation spectroscopy study of propylene glycol/ethanol binary mixtures: Temperature dependence. Spectrochim. Acta Part A: Mol. Biomol. Spectrosc. 2017, 179, 74-82.

19. Gabrielyan, L.S.; Markaryan, S.A. Dielectric relaxation spectroscopy study of the structure and dynamics of dialkyl sulfoxide solutions. Russian J. Phys. Chem. A 2018, 92, 205-213, 
20. Sadovnichii, D.N.; Milekhin, Y.M.; Malinin, S.A.; Voropaev, I.D. Some features of the dielectric relaxation of nitroglycerin. Combustion, Explosion, and Shock Waves 2017, 53, 49-54.

21. Murthy, S. N.; Tyagi, M. Dielectric study of the miscibility of binary liquids, one being an alcohol. J. Solution Chem. 2002, 31, 33-58.

22. Kaatze, U. Hydrogen network fluctions dielectric spectra of glycerol-ethanol mixtures. Chem. Phys. 2011, 403, 74-80.

23. Mohan, T.M.; Sastry, S.S.; Murthy, V.R.K. Thermodynamic, dielectric and conformational studies on hydrogen bonded binary mixtures of propan-1-ol with methyl benzoate and ethyl benzoate. J. Solution Chem. 2011, 40, 131-146.

24. Kurnia, K.A.; AbdulMutalib, M.I.; Murugesan B.T.; Ariwahjoedi, B.T. Physicochemical properties of binary mixtures of the protic ionic liquid bis(2-hydroxyethyl)methyl ammonium formate with methanol, ethanol, and 1-propanol. J. Solution Chem. 2011, 40, $818-831$

25. Alvarado, Y.J.; Luzardo, J.C.; Amado, G.F.; Labarca, V.M.; Michelena, E. Determination of the apparent molar refraction and partial molar volume at infinite dilution of thiophene-, pyrrole- and furan-2-carboxaldehyde phenylhydrazone derivatives in acetonitrile at 293.15 K. J. Solution Chem. 2007, 36, 1-11.

26. Farjtabar, A.; Faeli, M. Solvent effect on pronation of tppsin water-DMF mixtures. Bull. Chem. Soc. Ethop. 2016, 30, 457-464.

27. Sudake, Y.S.; Kamble, S.P.; Patil, S.S.; Khirade, P.W.; Mehrotra, S.C. Study of allyl chloride-2-butanone binary system using time domain refelectometry. J. Korean Chem. Soc. 2012, 56, 20-28.

28. Teller, A.J. Viscosities of benzene-methylethyl ketone systems. J. Chem. Eng. Data 1939, 4, 279-283.

29. Patankar, S.L.; Maharolkar, A.P.; Patil, A.G.; Murugkar, A.G. Study of thermophysical roperties of binary liquid mixtures. Malaysian J. Chem. 2018, 20, 148-153.

30. Reddy, G.S.; Reddy, R.S. Mahioxane with nitrobenzene at various temperatures using Mcallister model. Der Pharma Chemica 2014, 6, 135-139.

31. Maharolkar, A.P.; Murugkar, A.G.; Khirade, P.W. Dielectric and physicochemical characterization of nitrobenzene with DMSO. J. Chilean Chem. Soc. 2018, 63, 3841-3843.

32. Ramana, C.V.; Sekhar, T.C.; Kiran, A.B.; Malakondaiah, K. Dielectric and excess dielectric constant of binary liquid mixtures at 303 K. Phys. Chem. Indian J. 2008, 3, 7375 . 